\title{
DIREITO COMO UM SISTEMA DE NORMAS ARGUMENTATIVA E NARRATIVAMENTE CONSTRUÍDAS
}

\section{LAW AS A NORM SYSTEM BUILDED ARGUMENTATIVE AND NARRATIVELY}

\author{
${ }^{1}$ Jamir Calili Ribeiro \\ ${ }^{2}$ Thiago Costa Monteiro Caldeira
}

\section{RESUMO}

O artigo debate a utilidade da caracterização do direito como sistema de princípios e regras e propõe uma hermenêutica que mantenha o sistema jurídico autopoético, democrático e emancipador. Conclui-se que qualquer distinção entre espécies normativas baseia-se em critérios insuficientes. Defende-se que tais distinções são irrelevantes para se compreender o direito. Propõe-se perspectiva hermenêutica baseada na compreensão do sistema jurídico como prática argumentativa narrativa. O intérprete do direito deve construir a solução do caso levando em conta o passado e o futuro: coerente com o que já se construiu e indicativo do caminho que se quer tomar para o futuro.

Palavras-chave: Teoria dos princípios, Hermenêutica jurídica, Teoria do decisão

\begin{abstract}
The article is about understanding the law system as a system of principles and rules and about a proposed hermeneutics that can maintain the law's autopoiesis and its perspective democratic and emancipatory. It concluded any distinction between normative species is based in rational insufficiently criteria. Such distinctions are irrelevant to understand the law. Hermeneutic perspective proposed is based on understanding the law system as argumentative and narrative practice. The interpreter of the law must building a solution for case taking note about past and future: consistent with what is already built and indicative of the future that can be intended.
\end{abstract}

Keywords: Principles theory, Law hermeneutics, Legal decision theory

\footnotetext{
${ }^{1}$ Doutorado em Direito pela Pontifícia Universidade Católica de Minas Gerais - (PUC/MINAS), Minas Gerais (Brasil) E-mail: jamircalili@hotmail.com

${ }^{2}$ Secretaria de Aviação Civil - (SAC-PR), Paraná (Brasil) Mestrado em Regulação e Gestão de Negócios. Universidade de Brasília, Brasília (Brasil) E-mail: tcmcaldeira@yahoo.com.br
} 


\section{INTRODUÇÃO}

Todos os setores da investigação do Direito têm asseverado a existência de "princípios jurídicos", especialmente em contraponto às chamadas "regras jurídicas". Há uma repercussão significativa sobre esse tema, traduzida pela publicação de diversos artigos sobre os princípios jurídicos e sobre a distinção entre espécies normativas: princípios e regras. Porém, não se pode afirmar que tais debates tenham pacificado uma distinção relevante entre essas supostas espécies normativas.

No contexto contemporâneo o debate atual sobre a teoria dos princípios iniciou-se com Ronald Dworkin. Desde a edição do texto "O modelo de regras I" houve verdadeira ruptura do arcabouço jurídico positivista, descortinando uma perspectiva de hermenêutica crítica e pós-positivista. No Brasil, a distinção entre princípios e regras tem inspirado doutrina e decisões judiciais, especialmente amparados em textos de Robert Alexy.

Ocorre que, ao mesmo tempo em que se tem um amplo debate sobre a existência de diferentes espécies normativas e suas principais distinções, parece, em uma primeira constatação, que há na doutrina uma profusão de conceitos e classificações sobre regras e princípios, que os emprega de forma assistemática e não científica, utilizando-se da ponderação como meio para impor visões ideológicas ou perspectivas de vida sem qualquer compromisso com o processo deliberativo político.

A distinção adotada entre princípios e regras não é clara no âmbito dos debates estabelecidos na doutrina e, muitas vezes, há o uso impróprio das distinções teóricas já elaboradas, em um sincretismo perigoso e não sistematizado de forma adequada. Isso leva a alguns equívocos, como a exaltação exagerada da importância dos princípios, apequenando as funções das regras (GALUPPO, 2002; BUSTAMANTE, 2006; CRUZ, 2007; ÁVILA, 2012).

Além disso, a correlação feita entre princípios e valores leva à ideia de que o aplicador das normas poderá utilizar-se de apreciações subjetivas, o que tornaria a investigação judicial incontrolável (ÁVILA, 2012, p. 27-28).

Assim, um debate importante a ser realizado na construção de uma hermenêutica realmente interessada no desenvolvimento de um sistema jurídico autopoético de cunho democrático e emancipador deve se propor a debater se essa distinção entre princípios e regras é de fato relevante para a aplicação do direito e sua interpretação, bem como apresentar uma proposta que dê conta da complexidade da vida contemporânea, a qual exige alta carga de informação e respostas rápidas para as controvérsias sociais. 
Por um sistema jurídico autopoético, entende-se aquele sistema que opera pelo código binário lícito/ilícito, cognitivamente aberto a outros subsistemas sociais, mas operacionalmente fechado, tal como ensina Luhmann (2004).

A ideia democrática é aqui entendida sob a perspectiva pluralista, em contraponto à republicana, baseando-se na ideia de que embora impere a soberania popular - o consentimento do governado - os cidadãos podem perseguir seus interesses privados. Assim, o campo da política passa a ser o campo da construção de coalizões, para maximizar a satisfação dos interesses de cada um, respeitado o mínimo existencial e ético do sistema. Enquanto na democracia republicana visa-se sempre o bem comum, na democracia pluralista cada indivíduo pode expressar seus interesses e valores no mercado democrático, sendo que todos os projetos de vida são relevantes, desde que, repita-se, respeite-se um mínimo ético e existencial.

O viés emancipador desse sistema, portanto, combina com as ideias acima descrita, na medida em que os cidadãos devem ser protagonistas da solução dos seus próprios conflitos, responsáveis individuais pelos seus próprios destinos e livres para escolherem projetos de vida que considerem mais relevantes para sua felicidade.

Em grande medida parece ser esse o teor do paradigma iniciado com a entrada em vigor da Lei 13.105, de 16 de março de 2015, que institui o novo Código de Processo Civil. No anteprojeto do Código, a comissão de juristas responsável por sua elaboração alegou que "deu-se ênfase à possibilidade de as partes porem fim ao conflito pela via da mediação ou da conciliação". O entendimento era de que "a satisfação efetiva das partes pode dar-se de modo mais intenso se a solução é por elas criada e não imposta pelo juiz" (BRASIL, 2010, p. 22).

Nesse paradigma hermenêutico, a figura mítica de um juiz imparcial, incorrigível, isento, é substituída pela realidade descortinada pelas teorias contemporâneas da neurociência e da psicologia, incentivando a parte a encontrar solução para seus próprios conflitos. Mas, mais do que isso, descortina a falibilidade humana e de suas produções, incluindo nesse rol as construção legais abstratas e as decisões judiciais para os casos que lhes são apresentados.

Assim, o debate que se pretende neste artigo é pôr em questão a utilidade da diferença entre princípios e regras e apresentar um esboço de uma proposta hermenêutica que dê respostas para uma sociedade, nos termos de Kohlberg (1984), pós convencional, em que se reconhece a utilidade das regras, em especial para manter a ordem social e os direitos fundamentais, mas admite-se sua superabilidade, com base em justificativas universais. 
Não se pretende, por óbvio, desenvolver uma teoria hermenêutica totalmente singular ou completa neste artigo, mas esboçar pontos fundamentais para uma proposta que trate a aplicação do direito sobre um viés de integridade.

Ressalta-se que essa perspectiva não deixa de reconhecer a existência de uma gama enorme de cidadãos que são tratados pelo sistema econômico e político como subcidadãos, merecendo políticas compensatórias e inclusivas, especialmente em países em desenvolvimento como o Brasil.

Assim, o presente artigo se divide em duas partes: (a) questionar a utilidade da diferença entre princípios e regras, especialmente dentro do Direito Brasileiro; e (b) apresentar o esboço de uma proposta hermenêutica mais compatível com a realidade contemporânea, submetida aos cânones da Constituição de 1988.

\section{A DISTINÇÃO ENTRE PRINCÍPIOS E REGRAS ${ }^{1}$}

A distinção entre regras e princípios, especialmente entre os autores contemporâneos que adotam como marco teórico as teorias de Dworkin e Alexy, é defendida como uma alternativa ao positivismo. Em razão disso, apresenta-se um modelo interpretativo de operacionalização do Direito, baseado principalmente nos mecanismos de subsunção e ponderação.

O constitucionalismo do século XIX, especialmente influenciado pelas tradições revolucionárias francesas, com forte desconfiança ao conservador Poder Judiciário, absorvia os princípios como expressão de cunho político do legislador, sendo destacado o caráter mais político do que jurídico das Constituições, tal como a Declaração Universal dos Direitos do Homem e do Cidadão. A perspectiva jurídica do texto constitucional é uma contribuição muito peculiar do constitucionalismo americano, especialmente desde Madison v. Marbury (1803) (CRUZ, 2007, 272-273).

Mas logo se percebeu que o "soberano não pode, por certo, antecipar todas as contingências através de algum sistema de ordens; algumas de suas ordens são inevitavelmente vagas ou pouco claras" (DWORKIN, 2010a. p. 29).

O reconhecimento do caráter impreciso, indeterminado ou lacunoso do direito - ou seja, o reconhecimento da tessitura aberta dos textos legais e constitucionais - tornou inviável a pretensão de regulação de todas as condutas possíveis por meio de regras abstratas

\footnotetext{
1 Pressupõe-se que o leitor já esteja familiarizado com as distinções entre princípios e regras, afastando-se a repetição de teorias e argumentos já disponíveis. Sugere-se a leitura de RIBEIRO (2015).
} 
(CARVALHO NETTO, 2012, p. 45-48). Para lidar com essas indeterminações, antinomias e anomias, já que era impossível a priori a norma se adequar a todos os casos concretos, a teoria do direito, leia-se "os principais expoentes do positivismo", teve de admitir o emprego subsidiário de analogias, costumes e princípios gerais do Direito (CARVALHO NETTO, 2012, p. 48-51; DWORKIN, 2010a, 27-35; CRUZ, 2007, p. 274-275).

O ordenamento jurídico brasileiro traz como exemplo dessa influência a Lei de Introdução ao Código Civil $^{2}$, que admitiria a tese da discricionariedade, em que o juiz deveria optar por uma das possíveis respostas corretas apresentadas pelas partes para a solução do conflito, inicialmente difundida por Kelsen (1979, p. 467) e também admitida por Austin e Hart (DWORKIN, 2010a, p.48-51; TRIVISONNO, 2013, p. 199-200).

O paradigma liberal clássico, caracterizado por ignorar ou, no máximo, vislumbrar um papel secundário aos princípios jurídicos, começa a dar espaço a uma nova concepção no âmbito da teoria do direito (CRUZ, 2007, p. 271-272). Diante da insustentabilidade da subsunção integral e clara dos fatos à norma, positivistas e jusnaturalistas passam a reconhecer e admitir a força jurídica dos princípios.

A principal característica desse período é atribuir às distinções entre princípios e regras um critério de grau:

\begin{abstract}
Tradicionalmente, os critérios seguidos para justificar a distinção entre princípios e regras têm sido, entre outros, a generalidade, a indeterminação (elasticidade, indefinição, vagueza), a fundamentalidade, a alta hierarquia, o caráter correcional em relação às normas do sistema, a vinculação à "ideia de direito", o explícito conteúdo valorativo, a ubiquidade ou validade geral e a dificuldade da compreensão segura de seu significado. (FIGUEROA, 1998, p. 132, tradução nossa ${ }^{3}$ ).
\end{abstract}

Neste paradigma, é possível identificar vários critérios para se distinguir o que seja regra ou princípio, mas tudo gira em torno da distinção de graus: mais geral ou menos geral; mais fundamental ou menos fundamental; hierarquicamente superior ou inferior; mais indefinido ou menos indefinido etc.

A distinção fraca tem suscitado importantes críticas contra a sua validez racional e a sua utilidade. Foca-se neste trabalho em duas principais críticas: à ideia da vinculação dos princípios aos valores e à ideia de direito e justiça; e a generalidade dos princípios em relação às regras.

\footnotetext{
2 Atualmente nomeada de "Lei de Introdução às normas do Direito Brasileiro" com Redação dada pela Lei 12.376, de 2010 .

3 "Tradicionalmente, los critérios seguidos para justificar la distinción de los princípios respecto de las re glas han sido, entre otros, la generalidad, la indeterminación (elasticidad, indefinición, vaguedad), la fundamentalidad, la alta jerarquía, el carácter reformulatorio respecto de normas del sistema, la vinculación a la "idea del derecho", lo explícito de su contenido valorativo, la ubicuidad o la validez general, la dificultad de su conocimiento seguro,
} 
Segundo Cruz (2013, p. 276-277), a ideia de que os princípios vinculam-se a valores aborda critério insuficiente para se autorizar uma distinção racionalmente relevante. Isso porque, em primeiro lugar, como subsistema social, o Direito, por óbvio, reproduz valores sociais, sem operar-se pela sua lógica, sob pena de se perder sua legitimidade. De outro lado, é possível identificar em várias regras valores a elas subjacentes, tal como o valor à vida, presente no art. 121 do Código Penal.

Ao vincular os princípios aos valores, os juristas acabam por não diferenciar a própria norma do valor a ela subjacente, de modo que a operação do código binário lícito/ilícito, que diferencia o direito de outros subsistemas, é substituída pela lógica da gradualidade própria dos valores. Além disso, seria difícil em sociedades complexas e plurais como as contemporâneas, em especial as ocidentais, determinar qual é o ethos jurídico dominante, aquele que seria capaz de fornecer o norte para a aplicação do Direito sem o risco de promover a hierarquização cultural. O Direito, por meio das regras, acaba fazendo essa hierarquização, mas com base em um procedimento democrático profundo, ainda que imperfeito, ao contrário do Poder Judiciário, que acaba fazendo isso por meio do magistrado.

A ideia de generalidade incorre, também, em diversos erros. Neves aponta duas maneiras de se generalizar (2013, p. 22-23). A primeira, pelo raciocínio dedutivo, análogo aos axiomas ou postulados, considerando os princípios como normas evidentes da razão, mas sem comprovação empírica alguma. A segunda maneira, pelo raciocínio indutivo, "no qual os princípios emergem da generalização ou abstração sistemática a partir das regras existentes" (NEVES, 2013, p. 23). Esta maneira remete a um dos conceitos de princípios como regras fundamentais do sistema, extraído da generalização de regras.

Porém, tanto Cruz (2007, p. 278-280) quanto Neves (2013, p. 23-25) argumentam que a) nem todos os princípios podem ser generalizados a partir de regras; b) outros seriam tão generalizadores que englobariam todo o ordenamento jurídico, e não apenas um conjunto específico delas; e c) algumas regras seriam muito mais gerais que os princípios, já que muitos deles são setoriais.

Apesar destas críticas, a doutrina nacional tem repercutido de maneira acentuada as distinções fracas entre normas, especialmente destacando aqueles critérios que reforçam a importância dos princípios para o sistema jurídico.

Porém, é possível notar, nos últimos anos, no Brasil, uma tendência a abandonar essas concepções jurídicas, que, segundo Cruz, acabaram esbarrando "nas limitações da filosofia da consciência e nas insuficiências de uma hermenêutica, alienada da história efetual e do mundo 
da vida" (2007, p. 289). Assim, um novo conjunto de distinções tem sido apropriada pela doutrina brasileira, ainda que de maneira equivocada.

\subsection{A contemporânea abordagem de Dworkin: a irrelevância da distinção entre princípios e regras}

As abordagens contemporâneas têm se caracterizado pelo esforço em reafirmar a distinção entre regras e princípios a partir dos ganhos do giro linguístico, no sentido da construção de bases do que se poderia chamar de "pós-positivismo jurídico" (CRUZ, 2007, p. 271).

No campo do Direito, é revolucionária a contribuição de Dworkin com sua teoria dos princípios (NEVES, p.43-44), descrita em seus textos O Modelo de Regra I e O Modelo de Regra II (DWORKIN, 2010a). Para o autor norte-americano, o principal objetivo da distinção entre regra, princípio e política, mais do que criar uma classificação taxativa entre espécies de comportamento, foi afastar a perspectiva positivista de que só a regra tem conteúdo deontológico e suficiente para definir o que é o Direito de uma comunidade.

Em Justiça de Toga (2010b), Dworkin encara as críticas realizadas à insuficiência e irracionalidade de sua distinção entre princípios, regras e políticas afirmando que seus críticos não a compreenderam. Eis:

\footnotetext{
Referindo-me ao artigo de 1967, afirmei: "Não tive a intenção de dizer que 'o direito' contém um número fixo de padrões, alguns dos quais são regras, e outros princípios. $\mathrm{Na}$ verdade, quero contrapor-me à ideia de que 'o direito' seja um conjunto fixo de padrões de qualquer espécie. Em vez disso, pretendi afirmar que uma síntese acurada das ponderações que os juristas devem levar em conta ao decidirem uma questão específica de direitos e deveres legais incluiria proposições dotadas da forma e da força dos princípios, e que os próprios juízes e juristas, ao justificarem suas conclusões, empregam frequentemente proposições que devem ser entendidas dessa maneira (DWORKIN, 2010b, p. 331).
}

O alvo das críticas dworknianas era o positivismo doutrinário, responsável por definir quais teses e proposições podem ser consideradas normativamente válidas, e não o positivismo taxonômico, responsável por classificar alguma regra ou princípio como um princípio jurídico, tal como moral ou simplesmente matemático (2010b, p. 313). Nesse sentido, ele apresentou "o argumento doutrinário de que não podemos entender a argumentação e a controvérsia jurídicas exceto a partir do pressuposto de que as condições de 
veracidade das proposições de direito incluem considerações morais” (2010b, p. 331). Essa confusão entre o alvo de Dworkin, o doutrinário ou o taxonômico, segundo ele, provocou uma forte confusão e "é bem possível que um tempo enorme tenha sido desperdiçado" (2010b, p. 331). Conclui-se, ao reler a obra de Dworkin, que realmente houve um erro na interpretação de sua teoria ao se entender que a distinção entre regras e princípios seria essencialmente rígida e definitória da forma como se deveria interpretar o direito, ou aplicá-lo.

A distinção entre argumentos de política e de princípio, realizada tanto no Levando os Direitos a Sério, especialmente no capítulo sobre os Casos Difíceis, quanto em Uma questão de Princípio, especialmente no capítulo sobre Princípio, política, processo, parece ser mais contributivas do que a distinção entre regras e princípios, podendo-se afirmar que Dworkin sempre deixou claro essa posição. Neste sentido, buscou-se sempre reforçar o ataque geral ao positivismo e a ideia de que essa corrente de pensamento jusfilosófico tem sobre moral e direito. Para ele, "a estratégia de Raz se difere da de Coleman de maneira surpreendente: para Coleman, os juízes só estão comprometidos com a moral na medida em que o direito a incorpore, enquanto para Raz eles estão comprometidos com a moral a não ser na medida em o direito a exclui" (2010b, p. 333).

Como se pode notar, tanto em Raz como em Coleman reconhece-se que os juízes refletem sobre a moral ao tomarem uma decisão. Porém, para Dworkin, o fato de se reconhecer o reflexo da moral no direito não se pode retirar dele seu caráter eminentemente deontológico.

Não obstante as críticas que são realizadas a Dworkin, especialmente em relação à distinção entre espécies normativas, que como já se argumentou não passa pelo crivo de uma análise mais apurada da teoria do norte-americano, é preciso reconhecer os avanços que sua teoria trouxe à teoria do direito. A compreensão de Dworkin deve ser vista como contributiva para o rompimento com o modelo de regras positivista e a busca por uma hermenêutica contemporânea que seja capaz de absorver os ganhos da virada linguística.

A grande contribuição de Dworkin está em inaugurar essa perspectiva de que o rol de direitos de uma sociedade não está limitado ao previsto expressamente nas regras, além de que a perspectiva moral não pode ser simplesmente ignorada pelo aplicador do direito e os juízes não possuem ampla liberdade decisória em casos em que não há expressa previsão legal ou que argumentos utilitaristas e consequencialistas possam ser incorporados nas decisões judiciais a ponto de determinar a solução da controvérsia.

Assim, mesmo para Dworkin, a distinção normoteorética em abstrato é irrelevante, sendo importante reconhecer que não há apenas padrões normativos nas regras. Aliás, a nosso 
ver, nem existem enunciados normativos que, em abstrato, possam ser considerados como regras.

O debate sobre a distinção normoteorética só é relevante se for possível realizá-la em abstrato, antes da aplicação e da justificação. A distinção após a solução do caso pouco interessa. Em alguma medida, poder-se-ia reconhecer uma distinção entre as normas após a solução do caso, mas aí a distinção continuaria sendo irrelevante, pois não apresentaria nenhum ganho interpretativo. Nem mesmo poder-se-ia argumentar que a distinção faria sentido para um futuro caso a ser decidido, uma vez que o texto ou a norma ganhará sentido diverso conforme um novo caso surja, e por si só o texto, ou a norma, não é capaz de antecipar as condições de aplicação e justificação.

Admite-se, porém, que o termo princípio possa ser utilizada no campo argumentativo, tal como proposto por Cruz e Guimarães, para quem “os princípios podem assumir o significado de sumaes, cânones ou critérios (standards) no campo argumentativo, pois essa compreensão deriva do conceito de Hans-Georg Gadamer de experiência (...)" (2015, p. 156).

Também se pode admitir o uso do termo princípio como mera retórica para indicar importância de uma norma sobre outras, mas que só é possível de ser verificado dentro de algum jogo de linguagem específico, sem possibilidade de se atestar em abstrato essa importância. Parece ser esse último sentido o aplicado pela doutrina brasileira mais tradicional, uma vez que sequer há como contrapor princípios a regras, uma vez que, mesmo os princípios muitas vezes assumem o formato explícito de regras, como é o caso da legalidade e a anterioridade tributária.

\subsection{A abordagem Alexyana: a defesa da distinção entre princípios e regras e o retorno ao positivismo jurídico}

Tão ou mais impactante que a teoria de Dworkin na doutrina e jurisprudência brasileira, está a teoria dos princípios de Alexy, cujo conteúdo afirma uma proposta de reformulação da concepção dworkiniana de princípios, visando a sua aplicação na construção de uma teoria jurídica geral dos direitos fundamentais na Constituição alemã. $\mathrm{O}$ reconhecimento da ampla repercussão da teoria alexyana no Brasil não significa dizer que as pessoas a tenham compreendido de modo adequado.

A teoria dos princípios de Alexy propõe uma estrutura das normas de direitos fundamentais, utilizando-se da consagrada distinção entre princípios e regras. Para ele, "essa distinção constitui um elemento fundamental não somente da dogmática dos direitos de 
liberdade e de igualdade, mas também dos direitos a proteção, a organização e procedimento e a prestações em sentido estrito" (ALEXY, 2012, p. 85). É a coluna mestra do seu edifício da teoria dos direitos fundamentais. Na concepção do autor alemão, os princípios, como as regras, devem ser considerados como normas, pois dizem o que deve ser, podendo ambos serem formulados por meio de expressões deônticas. Caracteriza-se, portanto, como uma distinção entre duas espécies de normas e, ao contrário de Dworkin, para Alexy essa distinção é essencial e rígida.

Porém, a teoria do autor encontra diversas críticas, especialmente em relação à irracionalidade da distinção e dos métodos para encontrar a resposta correta:

\begin{abstract}
Alexy parece não perceber que, ao admitir possibilidades de que a lei da ponderação possa estabelecer-se de forma desconectada da realidade, sua teoria acaba definitivamente retornando ao paradigma positivista. Primeiro porque pretende cindir a interpretação em duas, eis que seu pós-positivismo se limita à aplicação dos princípios enquanto o emprego de regras ainda ficaria sob a égide do positivismo e de seus métodos de interpretação. Segundo, porque, ao dizer que as "regras de prevalência da ponderação" podem ser fixadas abstratamente em caráter definitivo, abandona qualquer perspectiva lingüístico-pragmática legada pela hermenêutica como analítica existencial, desde Heidegger e Gadamer. Logo, perdem-se até mesmo as condições de possibilidade para o conhecimento, que dirá então das condições de validade do mesmo (CRUZ, 2007, p. 295).
\end{abstract}

A postura alexyana resulta no retorno às noções de lacuna e discricionariedade próprias do positivismo ou, talvez, até a uma posição ainda mais permissiva em relação ao direito que os próprios positivistas não admitiriam (pelo menos em tese), baseada na desdiferenciação sistêmica entre direito e moral.

Esse argumento encontra respaldo em Carvalho Netto e Scotti, que afirmam que ao admitir que os princípios ensejam múltiplas possibilidades de decisões corretas, Alexy acaba admitindo que cabe ao aplicador escolher aquela mais conveniente (2012, p. 116-117).

O Habeas Corpus 82.424/RS, em que se discute a denúncia oferecida pelo Ministério Público do Rio Grande do Sul contra o Senhor Siegfried Ellwanger, sob a acusação do crime de “incitar e induzir a discriminação racial”, é paradigmático da insustentabilidade deontológica da teoria alexyana. Na ocasião, dois ministros - Gilmar Mendes pela condenação e Marco Aurélio pela absolvição - tomaram essas decisões totalmente opostas baseando-se na ponderação. Nesse sentido é que são dirigidas as críticas de Carvalho Netto e Scotti (2012) e Ommati (2012). Segundo este, o postulado da proporcionalidade não levaria a sério o Direito Moderno ao tratar direitos como valores, o que faria das decisões judiciais atos arbitrários, "decorrente de caprichos não refletidos e não fundamentados dos magistrados" $(2012$, 
As críticas à Alexy sustentam que a lei de colisão e ponderação implicaria uma concepção "axiologizante" do Direito, dependendo de o intérprete estabelecer o que deve ser preferido em detrimento de outro.

Jerzy Wrobléwsky (1974), dentre outros, argumenta que a teoria de Alexy não é da decisão, mas da justificação. Para Cruz e Guimarães, essa perspectiva facilita bem a aceitação dos argumentos de Alexy, sendo que "a aceitação das máximas da adequação, da necessidade e da ponderação cumpririam um papel de controle da decisão e não um papel de método para a tomada de decisão" (2014, p. 166).

Como teoria da justificação, e não como teoria da decisão, é preciso concordar que a teoria de Alexy apresenta pontos bem mais convincentes e representa um avanço sobre a perspectiva kelseniana. Mas Alexy, sob esse enfoque, continuaria supervalorizando a dimensão analítica da ciência jurídica, sendo que seu método acabaria por permitir que, pela ideia de um falso preenchimento de critérios racionais e matemáticos, o interprete encobrisse suas valorações subjetivas.

Também é necessário concordar com as críticas que se referem à insustentabilidade racional da distinção entre regras e princípios. Para Figueroa (2007), a tese forte da separação entre regras e princípios pode representar o calcanhar de Aquiles do arcabouço construído por Alexy, pois, ao mesmo tempo em que define um conceito deficiente de princípio, acaba enfraquecendo a descrição das regras. Esse paradoxo não seria exclusivo da teoria alexyana, mas de todas as teorias principialistas (2007, p. 346-347).

Se os princípios se distinguem das regras por dois critérios, o ontológico e o funcional, bastaria indicar um caso em que as regras foram objetos de ponderação ou que os princípios foram objetos de subsunção para derrubar todo o castelo construído.

Em outras palavras, uma teoria forte da separação deve enfrentar dois problemas básicos: a) as propriedades funcionais exclusivas das regras estão presente nos princípios; e b) as propriedades funcionais exclusivas dos princípios estão presente nas regras (FIGUEROA, 2007, p. 343).

O argumento de Figueroa passa pela abordagem sobre a admissão das exceções no modelo construído pelos principialistas, especialmente Alexy. Aponta uma questão que para ele seria chave para contaminar todo o modelo. Se nos Estados Constitucionais a Constituição irradia sobre todo o sistema, de modo a requerer interação entre princípios e regras, toda regra teria como possível exceção um princípio (jusfundamental), de modo que as regras acabam não sendo aplicadas como se fossem mandados de determinação, tornando a distinção 
supérflua e desnecessária. As exceções produzidas pelos princípios à aplicação das regras representariam o verdadeiro "cavalo de troia" para a distinção normoteorética proposta.

Mais grave, o conceito rígido de regra proposto acabaria levando à conclusão de que no Estado Constitucional não haveria regras, já que todas elas sofrem o efeito de irradiação dos princípios constitucionais. Logo, para ele não se poderia falar em regras genuínas, sendo, portanto, a distinção forte desnecessária, já que não é empiricamente verificada.

Aplicando-se a crítica a um exemplo nacional, pode-se recorrer ao caso objeto de análise no processo n 13003.000021/99-14, julgado pela $2^{\text {a }}$ Câmara do $2^{\circ}$ Conselho de Contribuintes, na sessão de 18 de outubro de 2000. A legislação tributária federal estabelecia que o ingresso no programa de pagamento simplificado de tributos federais implicava a proibição de importação de produtos estrangeiros. Desse modo, se uma empresa importasse determinado produto deveria ser excluída do programa de pagamento simplificado. Ocorre que, no caso julgado, uma pequena fábrica de sofás, enquadrada como empresa de pequeno porte, aderente ao programa de pagamento simplificado, efetuou a importação de quatro pés de sofás para um só sofá uma única vez. Contudo, o Conselho de Contribuinte não excluiu a empresa, afirmando que a adoção do comportamento por ela previsto não comprometia a promoção do fim que a justificava.

O Conselho de Contribuintes, ao interpretar a legislação federal sobre os requisitos para aderência ao sistema de pagamento simplificado, tratou o texto legal como se regra fosse, mas entendeu que a disposição trazia implicitamente a expressão "se a importação comprometer o fim que a justifica", ou seja, a exclusão do sistema de pagamento simplificado só seria possível se a importação colocasse em risco o fim que justifica a proibição da norma. Do ponto de vista lógico, poderia se concluir que se trata o dispositivo normativo de uma regra, mas do ponto de vista substancial o Conselho tratou a disposição textual como princípio, já que deveria levar em consideração vários outros princípios e políticas para determinar se uma importação particular em circunstâncias econômicas particulares comprometeria a finalidade normativa.

As argumentações produzidas por Alexy contra seus críticos acabam reforçando os argumentos contra a teoria, especialmente aqueles dirigidos à impossibilidade de controle intersubjetivo da decisão judicial, com base na fórmula peso e na teoria da ponderação, e a inviabilidade racional da adoção de uma dicotomia fechada entre dois tipos de normas, regras e princípios. O autor, embora retoricamente combata a perspectiva positivista do Direito, acaba dando continuidade aos elementos centrais do positivismo. 
A nosso ver, a distinção entre regras e princípios, além de não se dar em critérios verificáveis, não é útil, uma vez que só se vislumbra após a resolução do conflito, nunca antes, de forma abstrata, o que daria ensejo à escolha do melhor método de aplicação de uma norma, conforme sua espécie.

Ademais, a própria doutrina brasileira não construiu seu arcabouço de argumentos principiológicos baseado nessas distinções contemporâneas. Exemplo disto é o princípio da legalidade penal ou tributária, que mais se assemelham a regras do que a princípios. Assim, a mera operacionalização pelo método de subsunção ou ponderação não podem se guiar pela qualificação dada pela doutrina nacional às normas jurídicas, especialmente porque muitas vezes a construção da qualificação de uma norma como princípio não se dá em contraponto operacional e qualitativo das regras.

O que se pretende a seguir é lançar um esboço de proposta hermenêutica que prescinda dessas classificações, que reconheça a pluralidade da sociedade democrática contemporânea e, ao mesmo, não se afaste do ideal deôntico do subsistema do direito.

\section{UMA PROPOSTA HERMENÊUTICA ALTERNATIVA}

A proposta hermenêutica que se esboça prescinde da dicotomia entre espécies normativas do tipo regras ou princípios, assim como da distinção entre a aplicação do direito por modos operativos do tipo subsunção e ponderação. Faz-se uso das propostas capitaneadas pelo professor mineiro Álvaro Ricardo de Souza Cruz (Ver em especial CRUZ; DUARTE, 2013, p. 123-134; 199-219).

Desconstruindo a ideia da subsunção, Cruz e Duarte afirmam que, no máximo, o que pode ser defendido é que "fazemos associações mais diretas do que outras com alguns termos, dependendo do adestramento que recebemos, inclusive nos bancos das Faculdades de Direito" (CRUZ; DUARTE, 2013, p. 208).

Assim, sustentar a aplicação do direito pelo método da subsunção ou pela ideia da possibilidade dos casos fáceis seria um retorno à filosofia de "base mentalista" e, por consequência, à crença de que a linguagem meramente espelha ou representa a realidade (CRUZ; DUARTE, 2013, p. 201).

Com esse mesmo teor, críticas são direcionadas também à ponderação, uma vez que para Cruz e Guimarães a decisão judicial não é metódica, não havendo subsunção ou ponderação. Para os autores "a 'de-cisão' é fenômeno e sua 'justificação', em grande medida, 
observa o inferencialismo material para qualquer enunciado normativo" (CRUZ; GUIMARÃES, 2015, p. 184).

A ideia de que a ponderação levaria a uma decisão seria uma ilusão daqueles que acreditam em uma racionalidade pura e metódica, no mito de um juiz imparcial, incorrigível e neutro. Para Cruz e Wikrota, baseados em estudos e avanços da neurociência contemporânea, "mesmo as escolhas aparentemente mais refletidas se mostram fruto de esquemas mentais que não conseguem ser explicados como puramente racionais" (2015, p. 44). Assim, seguindo essas mesmas premissas, Cruz e Guimarães defendem que ponderação, tal como proposto por Alexy, é mero ato de justificar uma decisão, que é tomada antes mesmo de que se opere a ponderação (2015, p. 209).

Mesmo as regras possuiriam dimensão de peso, já que a dimensão axiológica não estaria circunscrita somente aos princípios, permeando todo o ordenamento jurídico. Não sendo a dimensão axiológica privativa dos princípios, as próprias regras, ou aquilo que se costuma chamar de regras, passariam por um processo de sopesamento. As interpretações extensivas e restritivas seriam um bom exemplo disso. A própria dimensão de peso não poderia ser aferida no princípio, mas atribuído a ele pela decisão em função das circunstâncias do caso (CRUZ, 2007, p. 301-302). Não sendo, portanto, atributo empírico das normas que são chamadas de princípios, não há como justificar uma diferença lógica relativamente às regras com base nessas características.

A partir dessas perspectivas, propõe-se considerar o sistema jurídico como um sistema composto de normas, sem a necessidade de qualquer diferenciação ontológica ou funcional, ou seja, de mandamentos que definem licitude e ilicitude, utilizando-se de enunciados normativos diversos.

Admite-se, porém, que alguns enunciados veiculam normas de direitos fundamentais em contraponto a outras normas, o que não significa dizer que tais enunciados mereçam uma veiculação em uma forma especial ou que sua aplicação se dê de modo funcionalmente diferente das outras normas. O que diferenciará uma norma de direito fundamental de outra será a consideração na prática interpretativa de que aquela norma fundamental possui elementos de irreversibilidade e imodificabilidade restritiva. ${ }^{4}$

\footnotetext{
${ }^{4} \mathrm{Na}$ ADIn. 9.397, por exemplo, o STF interpretou as limitações constitucionais ao poder de tributar, bem como as imunidade previstas na Seção II do Capítulo I do Título VI da CF como direitos fundamentais irreversíveis, imodificáveis por meio do poder derivado de emenda e reforma. Nessa seção, por exemplo, nada se fala acerca da não cumulatividade. Ora, poder-se-ia debater se a não cumulatividade pode ser interpretada como um princípio, estendendo ou não, portanto, as conclusões do STF para aquelas normas para as normas da não cumulatividade. Na seara do Direito Penal, discute-se se a maioridade penal prevista no art. 228 da Constituição Federal é garantia individual de modo que sua redução fosse inconstitucional. O debate, portanto, não é uma
} 
Na esteira dos ensinamentos de Cruz, porém, é preciso admitir uma discricionariedade num sentido fraco, e é preciso fazer uma releitura da segurança jurídica, baseando-a na validade e na adequação de argumentos justificadores do programa normativo. Não é possível, do ponto de vista pragmático, acreditar que exista um "porto seguro" baseado em métodos ou modelos a priori (CRUZ, 2011, p. 231). Para Cruz, é possível admitir uma renovação do conceito de método, abandonando a ideia de um caminho sequencial, previamente concebido, que serve mais para referendar uma decisão já tomada do que para encontrar a resposta correta, substituindo-o pela fenomenologia ou pela dialética contemporânea, esta que vai além da fragmentação das categorias aristotélicas e/ou kantianas (CRUZ, 2011, p. 232).

Portanto, embora não se possa defender um estacionamento em um porto seguro sustentado pela racionalidade tal como a ilusão iluminista propunha, "o controle argumentativo é imprescindível em um Estado Democrático de Direito" (CRUZ; DUARTE, 2013, p. 209). Não se pode negar aos interessados o direito de compreender os fundamentos que levam seus direitos a serem reconhecidos ou negados. A proposta de Cruz para que se evite o decisionismo passa pela defesa de um controle argumentativo participativo, por meio de uma perspectiva crítica deliberativa, tal como defendido por Habermas (CRUZ; DUARTE, 2013, p. 209).

Uma vez que os fundamentos que levam os direitos a serem reconhecidos ou negados são estabelecidos dentro da prática argumentativa, é preciso que esses fundamentos sejam levados à sério e suas modificações ocorram dentro de um controle participativo que assegure, também, a confiança daqueles que pautaram suas condutas por eles.

Essa nova hermenêutica não precisa ser baseada em distinções de regras e princípios, pois o próprio conceito semântico de regra seria anacrônico, diante da insuficiência do “cálculo" exegético (CRUZ, 2011, p. 232). A decisão judicial, porém, deve sempre se basear em "argumentação de princípios", sendo fundamentada na "filosofia da linguagem, concretista e aberta, livre, pois, dos padrões formalistas e subsuntivos do positivismo e da filosofia da consciência" (CRUZ, 2007, p. 322).

É claro que questões ainda permanecem, como as seguintes: Quando o intérprete sabe que encontrou a resposta correta? (CRUZ, 2011, p. 232); e É possível defender a ideia de resposta correta? (CRUZ, 2011, p. 235).

questão de fato, como se fosse possível estabelecer um critério semântico para identificar uma norma como direito fundamental ou não. A questão é interpretativa. 
O certo é que a "resposta correta" jamais se dá ex ante ou que pode ser havida como ficção ou estratégia política. A resposta deve ser encontrada dentro de um "jogo" específico de linguagem. Não se pode admitir nem os "consequencialistas fortes", que conduziriam a uma desdiferenciação, e tampouco seriam admitidos os métodos tradicionais da subsunção ${ }^{5}$ ou da ponderação.

A decisão não é um ato, mas "um procedimento. (...) Quando lemos um processo, a decisão se apresenta a nós como um acontecimento, como um fenômeno" (CRUZ, 2011, p. 233). Para ele, "esse insight, esse clique, essa clareira se apresenta a nós sem que possamos explicar essa ocorrência" (CRUZ, 2011, p. 233).

Como os juristas são treinados ostensivamente para lidar com métodos, abertos a argumentos utilitários e consequencialistas fortes, tomam suas decisões, lamentavelmente, até mesmo antes de ler as razões contrárias e redigem seus votos "racionalmente", sem se darem conta de que estão apenas a justificar tecnicamente aquilo que se deu como um fenômeno (CRUZ, 2011, p. 233).

Cruz defende, então, que se admita que a sentença seja uma decisão fenomenológica e que a decisão não possa ser tomada a partir de um método e de argumentos estranhos ao jogo do direito, fazendo com que o intérprete seja obrigado a se mostrar, a se desvelar, a julgar seus próprios preconceitos, reforçando-os ou superando-os, a julgar a interpretação da Corte Superior e a manifestar por que concorda ou discorda dela, sem reproduzir acriticamente as decisões já tomadas (CRUZ, 2011, p. 234). Apontando criticamente um caminho, Cruz e Wikrota afirmam:

(...) O juiz precisa justificar sua "de-cisão". Precisa explicar seus fundamentos. Torná-la razoável para o auditório. Precisa se justificar diante do Outro e do Terceiro.

É quando automaticamente "aplica" as técnicas interpretativas que aprendeu na Academia.

(...)

Em seu poder, o juiz "pode" justificar sua decisão. E ao justificar convence o Outro de sua racionalidade. Assim foi e assim tem sido. Bom senso, phronesis, razoabilidade, equidade! Tudo é consciência!

Tudo? Tudo mesmo? Não ficaria nada de fora? Não "há" nada mais a ser "dito". Il y

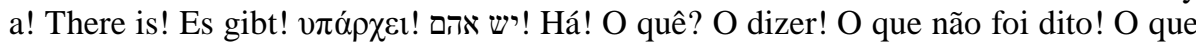
não foi revelado. $\mathrm{O}$ olhar da testemunha. A compaixão pelo sofrimento alheio. $\mathrm{O}$ orgulho de ser o melhor. A vaidade de impor sua vontade. A cobiça! A volúpia! O desejo! Não há compreensão sem afecção. Não há compreensão sem criação. Não há compreensão sem ética.

\footnotetext{
5 "Não se trata, pois, de dizer que o problema é mera implicância dos autores com a palavra 'subsunção'. O que está em jogo é aquilo que a crença na subsunção traz consigo e com ela o prejuízo na análise da aplicação do direito. Crer na subsunção implica crer que a interpretação é metódica, o que vela a infinitude que expressa esse evento" (CRUZ; DUARTE, 2013, p. 213).
} 
O "dizer" denuncia o "dito" iluminista que pretende reduzir a "de-cisão" a sua “justificação racional”. O "dizer" revela o mito iluminista de equiparar o "ser da decisão" ao ente de sua justificação!

A "de-cisão" é diferente do esforço que é preciso ser feito para o controle argumentativo daquilo que foi decidido, que a tradição iluminista costuma chamar de "justificação". Mesmo sabendo que não há uma divisão clara entre esses momentos de "de-cisão" e "justificação", podemos assumir que, depois de decidido é possível refletir sobre aquilo que se decidiu e se deve, então, partir para o esforço de rever o que foi decidido e para se permitir que outros examinem alguma fundamentação a título de controle. Aqui a dimensão de "justificativa" permite o controle argumentativo daquilo que foi decidido, até mesmo para uma reflexão sobre a etapa de adequação pelo filtro ético (CRUZ; WRIKOTA, 2015, p. 53-54).

Ao invés de adotar um método, a reviravolta linguística não aponta um trajeto para se chegar à "resposta correta", mas indica caminhos a não serem seguidos. A "pretensão de correção" se dá pelo modo dialético, "como mecanismo de alerta para aquilo que não deve ser tentado ou repetido" (CRUZ, 2011, p. 234). Espera-se que o intérprete acabe aprendendo com a crítica, fazendo-o não cometer mais erros e ensinando-o a identificar argumentos e argumentações que não fazem parte do Direito.

Quanto à questão de ser possível uma resposta correta, é preciso se posicionar afirmativamente à questão, tal como Cruz. Só que a resposta correta não é um “chegar a”, mas um "caminhar para", o que pressupõe que a resposta dada para aquela situação contingente no tempo e no espaço é a resposta correta. Correta não por ser ontologica ou metafisicamente correta, mas correta pois assim se "a-presenta". É uma resposta provisória, e sujeita a críticas (CRUZ, 2011, p. 235-236).

Porém, como fugir do decisionismo? Viver é correr o risco. Uma sociedade emancipada sabe de seus riscos e nesse sentido é preciso construir a confiança sistêmica numa arrojada arquitetura participativa que reconheça que: (a) toda decisão tem consequência e isso significa dizer que tanto participar quanto não participar implica em deveres e direitos a serem assumidos por todos; (b) que vivemos em uma sociedade plural; (c) que o Estado, tanto o executivo quanto o legislativo e o judiciário, não são formados por seres muito diferente de nós, que possuam o controle da sabedoria plena, logo não são capazes de planificação da sociedade; e (d) que é preciso desenvolver métodos de solução de conflitos que deem preferência às alternativas produzidas pelos próprios envolvidos.

Dessa forma, parece ser, sim, possível fugir do decisionismo. Defende-se que os intérpretes devem mudar sua perspectiva sobre os conceitos jurídicos. Eles seriam peças de um tabuleiro construído por essas mesmas peças, de modo que não se trata de adotar uma postura baseada no know that, mas no know how. 
Não se pode compreender a norma jurídica como um conceito estanque de um só caso, mas o conceito, sentido provisório, que aquela comunidade desenvolve ao longo de sua história. Assim, será possível perceber se um juiz foi discricionário ou não, subjetivo ou não, pela história que se formou, pelas interpretações que diversos atores deram àquela prática. Porém, não há controle absoluto. Os equívocos na interpretação, em um sistema processual participativo, não são tão grandes a ponto de comprometer a prática social como um todo (DWORKIN, 2007, p. 322).

É no plano pragmático da linguagem que se pode aferir e construir as significações, rejeitando-se a ideia de conceitos determinados e indeterminados em si mesmos. Toda a argumentação pode ser considerada, desde que "dentro da linguagem deontológica" (CRUZ; GUIMARÃES, 2014, p. 222). A semântica não é descartada. Ocorre que a semântica passa a ser associada aos demais aspectos analíticos da linguagem, como a sintática e a pragmática.

Isso significa que os conceitos não podem ganhar qualquer conotação. A prática jurídica argumentativa é uma narrativa, que se associa muito à ideia do direito como romance em cadeia, em contraponto à argumentação como justificativa.

Assim, é importante a distinção entre argumentos de princípios e argumentos de política para a compreensão do processo de tomada de decisões, seja pelo Legislativo, seja pelo Judiciário. A preponderância dos argumentos de princípio no debate judicial é correta, uma vez que deve-se reconhecer que os juízes não podem agir discricionariamente na solução de um caso, não possuindo ampla liberdade decisória. É necessário reforçar: não se trata de admitir que os conceitos são igualmente flexíveis, ou que todo tipo de argumentação é admissível. Há aspectos a serem considerados, como expressões linguísticas cujo uso é menos flexível e cuja alteração pragmática de conteúdo é mais restrita ${ }^{6}$, como é o caso de ramos jurídicos como o Penal e o Tributário, em que a legalidade estrita possuem peso jurídico singular.

\footnotetext{
${ }^{6}$ Rigidez que pode ser verificada pela análise do discurso da tradição jurídica da doutrina brasileira e do sistema jurídico constitucional adotado. Adota-se o termo inspirado em Wittgenstein (2002) e nas lições de Cruz (2011; 2007; 2013; 2014 e comunicações orais em sala de aula). Ávila destaca a rigidez e a exaustividade como características peculiares do sistema tributário: "O sistema tributário nacional é um sistema rígido. Essas há muito conhecidas rigidez e exaustividade decorrem de dois fundamentos: de um lado, as regras de competência e a repartição das receitas são intensamente reguladas pela própria Constituição. (...) De outro, a instituição dessas regras de competência em nível constitucional conduz a uma rigidez modificativa do Sistema Tributário Nacional. (...) A rigidez específica das normas tributárias é também direta e indiretamente instituída: algumas são denominadas "garantias" (art. 150: legalidade, igualdade, irretroatividade, anterioridade, proibição de tributo com efeito de confisco, imunidades); outras normas mantêm relação com os princípios fundamentais (princípio federativo, democrático e da separação dos poderes) ou com os direitos e garantias individuais cuja modificação é vedada"

(Ávila,

2011,

p.

163-164).
} 
A argumentação como narrativa, a nosso ver, é adequada para o conceito que se desenvolve do direito como romance em cadeia e sob a perspectiva da integridade ${ }^{7}$. O julgador não buscará um desculpa para a sua aplicação e decisão, mas deve agir com responsabilidade, e dar coerência ao direito.

\section{CONCLUSÃO}

Tal como em Dworkin, defende-se que a construção argumentativa de um caso jurídico está aberta a diversas possibilidades de leitura, mas isso não significa que o intérprete não possa encontrar no caso a resposta correta, no sentido de uma decisão que possa ser a mais adequada e justa para aquele conjunto de pretensões que as partes deduzem no conflito. E não significa que os observadores do sistema jurídico não possam criticá-la de maneira que a decisão possa ser considerada como incorreta, ainda que não haja mais a possibilidade de se rediscuti-la no âmbito processual.

Ressalta-se que a possibilidade de se encontrar no caso uma resposta correta pressupõe, também, a possibilidade de erro. Isso não danifica o sistema como todo, exceto se essas decisões equivocadas não possam ser revistas ou se ainda que revistas sejam decisões que possam desdiferenciar o sistema jurídico em relação a outros sistema como a moral, economia ou política.

As propostas de um debate sobre os argumentos de princípios e os argumentos de política são úteis para uma hermenêutica que se ajuste ao Estado Democrático de Direito, especialmente em razão dos bens jurídicos protegidos, como vida, liberdade e propriedade. A dinâmica da solução do caso deve levar em conta direitos, e não objetivos políticos, embora esses possam ser razões para a instituição de direitos e de deveres.

Como consequência deste raciocínio, é de se concluir que os juízes não podem agir discricionariamente na solução de um caso, nem possuem ampla liberdade decisória, sendo muito útil para o direito a proposta de direito entendido metaforicamente como romance em cadeia (DWORKIN, 2007, p. 275). A ideia é que a legitimidade se dá pelo convencimento, e não apenas pela coação. $\mathrm{O}$ direito possui fundamento ético, não sendo a moral meramente

\footnotetext{
7 "O que o julgador faz é uma narrativa, não uma justificação. Mas, enquanto narrativa, a 'de-cisão' se torna promessa de justiça. Ela se torna íntegra pelo compromisso ético de justiça. Ela não 'é' ato de cognição nem tampouco atitude cínica. O Outro e o terceiro não são fantoches. A narrativa expõe o juiz. Expõe sua evasão. Testemunha sua epifania. Se vem das sombras do inconsciente, se é fenômeno, também joga luzes sobre o que foi dito e o que ficou por dizer. Permite o diálogo, pois é abertura ao Outro. Autoriza o 'debate' de razões. Questiona a ontologia empregada. Exige a revelação do que se esconde pelas paredes do 'túnel do processo'. Pede a visão dos invisíveis, a inclusão dos excluídos" (CRUZ; WYKROTA, 2015, p. 55).
} 
contingencial, pois a solução de conflitos não pode ser meramente técnica, mas justa e legítima.

O intérprete do direito, seja ele o juiz ou a doutrina, deve construir a solução do caso levando em conta o passado e o futuro, de forma que a solução seja coerente com o que já se construiu e suficientemente indicativa do caminho que se quer tomar para o futuro. Nesta perspectiva construtivista, embora se deva dar valor aos precedentes, não há a obrigatoriedade de serem aplicados e não há impedimentos para sua superação (overrulling), desde que seja necessário que a decisão judicial integre-se de modo harmônico ao sistema jurídico (DWORKIN, 2007, p. 274).

E por fim, como já se debateu e aqui conclui, para essa perspectiva hermenêutica basta que considere-se a existência de normas no sistema jurídico, podendo alguns preverem direitos fundamentais dos indivíduos e outras não, sendo irrelevante qualquer tipo de classificação dessas normas em espécies, tais como regras, princípios, políticas ou postulados. 


\section{REFERÊNCIAS}

ALEXY, Robert. Teoria dos Direitos Fundamentais. São Paulo: Malheiros, 2012.

ÁVILA, Humberto Bergmann. Sistema Constitucional Tributário. 5a ed. São Paulo: Ed. Saraiva, 2011.

ÁVILA, Humberto. Teoria dos princípios: da definição à aplicação dos princípios jurídicos. $13^{\mathrm{a}}$ ed. São Paulo: Malheiros, 2012.

BRASIL. Congresso Nacional. Senado Federal. Comissão de Juristas Responsável pela Elaboração de Anteprojeto de Código de Processo Civil. Código de Processo Civil: anteprojeto. Brasília: Senado Federal, Presidência, 2010.

BRASIL. Ministério da Fazenda, Acórdão n. 104-21.675 da $4^{a}$ Câmara do $1^{\circ}$ Conselho de Contribuintes, proferido na Sessão de 22.06.2006, Relator Nelson Mallmann, ementa disponível em: <http://www.conselhos.fazenda.gov.br>. Acesso em: 16.jul. 2014.

BUSTAMANTE, Thomas da Rosa de. Princípio, regras e a fórmula de ponderação de Alexy: um modelo funcional para argumentação jurídica? Revista de Direito Constitucional e Internacional, São Paulo, v.14, n.54, p.76-107, jan./mar.2006.

CARVALHO NETTO, Menelick de; SCOTTI, Guilherme. Os Direitos Fundamentais e a (In) Certeza do Direito. A produtividade das tensões principiológicas e a superação do sistema de regras. Belo Horizonte: Editora Fórum, 2012.

CRUZ, Álvaro Ricardo de Souza. Regras e princípios: por uma distinção normoteorética. In: Hermenêutica Jurídica e(m) Debate: o constitucionalismo brasileiro entre a teoria do discurso e a ontologia existencial. Belo Horizonte: Fórum, 2007.

CRUZ, Álvaro Ricardo de Souza; DUARTE, Bernardo Augusto Ferreira. Além do Positivismo Jurídico. Belo Horizonte: Arraes, 2013.

CRUZ, Álvaro Ricardo de Souza; GUIMARÃES, Ana Carolina Pinto Caram. Regras e Princípios: Uma visão franciscana. In: CRUZ, Álvaro Ricardo de Souza Cruz (Coord). Nos corredores do direito. v.1. Belo Horizonte: Arraes Editores. 2015, no prelo.

CRUZ, Álvaro Ricardo de Souza; WIKROTA, Leonardo Martins. Nos corredores do direito. In: CRUZ, Álvaro Ricardo de Souza Cruz (Coord). Nos corredores do direito. v.1. Belo Horizonte: Arraes Editores. 2015, no prelo.

DWORKIN, Ronald. A justiça de toga. São Paulo: Martins Fontes, 2010 b.

DWORKIN, Ronald. Levando os direitos a sério. São Paulo: Martins Fontes, 2010a.

DWORKIN, Ronald. O império do direito. São Paulo: Martins Fontes, 2007.

FIGUEROA, Alfonso García. Principios y positivismo jurídico: el no positivismo principialista en las teorías de Ronald Dworkin y Robert Alexy. Madrid: Centro de Estudios Políticos y Constitucionales; 1998. 
FIGUEROA, Alfonso García. ¿Existen diferencias entre reglas y princípios en el Estado Constitucional? Algunas notas sobre la teoría de los princípios de Robert Alexy". In: Alexy, Robert et alli., Derechos sociales y ponderación, Madri: Fundación Coloquio Jurídico Europeo, 2007.

GALLUPO, Marcelo Campos. A Teoria Discursiva do Direito e a Renovação do Conceito de Princípios Jurídicos. In: Igualdade e diferença. Estado Democrático de Direito a partir do pensamento de Habermas. Belo Horizonte: Mandamentos, 2002.

KOHLBERG, L. The Psychology of Moral Development: The Nature and Validity of Moral Stages. (Essays on Moral Development). v. 2. New York: Harper \& Row, 1984.

LUHMANN, Niklas. Law as a Social System. Klaus A. Ziegert (trad.). Oxford: Oxford University Press, 2004.

NEVES, Marcelo. Entre hidra e Hércules: Princípios e Regras Constitucionais. São Paulo: Editora WMF Martins Fontes, 2013.

OMMATI, José Emílio Medauar. Liberdade de expressão e discurso de ódio na Constituição de 1988. Rio de Janeiro: Editora Lumen Juris, 2012.

RIBEIRO, Jamir Calili. Princípios Jurídicos Tributários. Belo Horizonte: D’Plácido. 2015.

TRIVISONNO, Alexandre Travessoni Gomes. Princípios jurídicos e positivismo jurídico: as críticas de Dworkin a Hart se aplicam a Kelsen? In: OLIVEIRA, J. A.; TRIVISONNO, A. T. G. Hans Kelsen: Teoria Jurídica e Política. Rio de Janeiro: Forense Universitária, 2013.

WROBLÉWSKY, Jerzy. Legal syllogism of rationality of judicial decision. In Rechtstheorie 1, 1974. 